\title{
Working \& Sustaining the Virtual "Disaster Desk"
}

\author{
Kate Starbird \\ ATLAS Institute \\ University of Colorado, Boulder \\ Boulder, CO 80309-0430 \\ kstarbi@uw.edu
}

\author{
Leysia Palen \\ Department of Computer Science \\ University of Colorado, Boulder \\ Boulder, CO 80309-0430 \\ palen@colorado.edu
}

\begin{abstract}
Humanity Road is a volunteer organization working within the domain of disaster response. The organization is entirely virtual, relying on ICT to both organize and execute its work of helping to inform the public on how to survive after disaster events. This paper follows the trajectory of Humanity Road from an emergent group to a formal nonprofit, considering how its articulation, conduct and products of work together express its identity and purpose, which include aspirations of relating to and changing the larger ecosystem of emergency response. Through excerpts of its communications, we consider how the organization makes changes in order to sustain itself in rapid-response work supported in large part by episodic influxes of volunteers. This case enlightens discussion about technology-supported civic participation, and the means by which dedicated long-term commitment to the civic sphere is mobilized.
\end{abstract}

\section{Author Keywords}

Civic participation; crisis informatics; CSCW; digital volunteers; knowledge commons; virtual organizations

\section{ACM Classification Keywords}

H.5.3 Groups \& Organization Interfaces - collaborative computing, computer-supported cooperative work; K.4.2 Social Issues

\section{General Terms \\ Design; Human Factors}

\section{INTRODUCTION}

In the aftermath of the 2010 Haiti earthquake, a group of geographically dispersed people came together after discovering each other through social media as they individually tried to aid the response efforts [26]. For a small number of these digital volunteers, their emergent work progressed to a point of formalization that included division of labor and coordinated activity [15], shifting soon after into an incorporated non-profit organization

Permission to make digital or hard copies of all or part of this work for personal or classroom use is granted without fee provided that copies are not made or distributed for profit or commercial advantage and that copies bear this notice and the full citation on the first page. To copy otherwise, or republish, to post on servers or to redistribute to lists, requires prior specific permission and/or a fee.

CSCW '13, February 23-27, 2013, San Antonio, Texas, USA.

Copyright 2013 ACM 978-1-4503-1331-5/13/02...\$15.00. called Humanity Road. Their intention was to continue to support Haiti relief after international attention faded, and then prepare to support other crises and humanitarian events internationally. Early in its life, group members began organizing themselves around information tasks that could be performed entirely online; these included verification of information, routing of information to those who could act on it, and matching of publicized needs to offers.

Today Humanity Road remains an entirely virtual organization with a global membership of volunteers in support of humanitarian relief. Virtual organizations are "geographically distributed [organizations] whose members are bound by a ... common interest or goal, and who communicate and coordinate their work through information technology" [1]. Describing the from-scratch conditions of virtual organizing, Finholt et al. write that the "absence of prior structure means group members must develop new structures for sharing information, for example, norms or rules for reporting progress and division of labor" [8 p. 292]. As a virtual organization, Humanity Road has grown from improvised ways of operating in the chaotic information space of disasters to an increasingly established organization with a steadier social structure, identity, production functions, rules and procedures.

This paper accounts for the progression of Humanity Road from the point after its emergence as a set of loosely connected individuals as first described in [26] to a virtual organization of both long-term and episodic volunteers. Through analysis of the group's communications, we consider how its members manipulate the social mediabased information that is produced during and after disaster events in an effort to create information resources for victims and responders - and to demonstrate to emergency management that such resources are valuable and such volunteer work is possible.

\section{Social Computing in a Virtual Volunteer Organization} Exploring relationships between traditional volunteer (nonprofit) organizations and social computing, Voida et al. [27] report that these organizations, contrary to the perceptions of many, do not need help recruiting new volunteers - a perceived application of social media tools. Volunteer coordinators feel that the "episodic" volunteering encouraged by public, "all call" social media broadcasts is not useful to them. Instead, they see potential for social computing to help them meet other priorities, including 
fostering community among current volunteers and supporting a deep engagement with these volunteers. Voida et al. [27] describe this potential of social computing as yet unrealized in traditional non-profit organizations.

But what of the purely virtual, volunteer organization? Humanity Road (HR), an early member of the emerging ecosystem of virtual volunteer humanitarian response groups, provides an opportunity for examining this relationship between volunteerism and social computing in a virtual, non-profit organization. Virtual organizations rely entirely upon social media and other ICT for their organizing, and for HR, these tools are tightly woven into the social structure of the organization-shaping who they are, what they do and how they do it.

HR represents an opportunity for exploring virtual volunteerism within a domain for which it may be particularly well suited. Response and relief work is characterized by convergence of people, information and resources. It is also characterized by improvisation, with volunteers and formal responders alike innovatively adapting to unique and changing conditions, using resources in new ways, taking on new tasks and assembling into new organizational forms $[7,9,15]$. During disasters, many physically located on-lookers shift into roles of helping $[7,9,14]$ and we see the same in the online arena [12]. HR emerged from digital, spontaneous volunteerism [26], which remains a constitutive element of the organization. Their continued incorporation of spontaneous volunteers intentionally differs from how traditional volunteer organizations, specifically the American Red Cross, function.

Additional features of the disaster domain are that action is often fast-paced and social structures are emergent [15]. We see the same in online social convergence, and because of the traces of the digital communication they leave behind, examination of the small but rapidly graduating steps from social convergence to social organization are detectable.

This paper follows the trajectory of HR from an emergent group as first described in [26], to a formal non-profit, now considering how its work, its articulation of work, and the ICT it adopts in order to operate in and on the virtual sphere are interrelated, and how they together express the virtual organization it has become. Throughout, we maintain a particular focus on how the organization sustains itself over time in a domain that is comprised of a set of long-term volunteers as well as a regularly changing corps of episodic volunteers who "spontaneously" converge in response to individual disasters [9]. The case of HR enlightens the discussion around what is possible - or not possible-with technology-supported civic participation over an extended period of time, and the means in which dedicated long-term commitment to the civic sphere is mobilized.

\section{RESEARCH: METHOD \& ANALYTICAL FRAME}

\section{Participant Observation}

This study is based primarily upon participant observation by the first author, who spent more than 16 months as a participant observer within HR, taking part in several efforts to respond to disaster events in 2011 and 2012. In this capacity, she acts both as a digital volunteer within and as a researcher of the organization. When interacting within the group's Skype windows, she makes this dual role explicit in her handle, which appears to all conversation participants as Kate Starbird - student/researcher.

In addition to field notes, the primary data are the digital traces of communication that HR members leave behind via their online interactions. The environments they use include Skype, Google Docs, Twitter, and their own webpage. Most of these tools maintain archives of interactions, which are our data sources. To capture Twitter data related to HR, this research used custom Twitter search software [2] to collect the full tweet streams of each HR volunteer during the length of the study, and to execute keyword searches during specific disaster events to which the group responded.

Usernames and Twitter accounts are pseudonymous here. However, with their permission, HR leaders Graham and Thompson are explicitly recognized.

\section{Interpretive Frame}

We employ the analytical lens of structuration to help explain the evolution of HR from a loose band of helpers to a coordinated, sustained organization of volunteers, as evidenced in illustrative excerpts.

Giddens' theory of structuration explains how social structures, defined as rules and resources or transformational relations, are both the products and the pathways of human action [10]. Employing the concept of duality of structure, Giddens contends that social action both shapes and is shaped by these structures. Orlikowski [20] provides a duality of technology framework for applying structuration theory to research on the role of information technology (IT) within organizational change, where IT is both the product of human action and a medium of human action, functioning to enable and constrain it. The communication constitutes organization perspective again extends structuration to communicative processes, claiming that communication and the organization co-produce and co-adapt [23], and provides a helpful approach for examining organizing within the virtual organization though the digital traces of its communication [4].

\section{OBSERVATIONS}

\section{Origins of Humanity Road:}

From Social Convergence in Response to Disasters

Though HR incorporated in April 2010, its origins can be traced to 2005, when Catherine Graham and Christine Thompson, recognizing deficiencies in efforts to meet informational needs of affected people, deployed "Internet Cafés" for disaster victims of Hurricane Katrina [13]. Then, 
in the summer of 2009, Thompson was among a small group of volunteers who converged on-line to help provide first-aid information to people involved in the Iran Election protests. Less than a year later, the January 12, 2010 Haiti earthquake catalyzed a core group of online volunteers including Graham and Thompson. A subset of this cadre who found each other through Twitter, and soon identified as voluntweeters or crisis tweeters, went on to become the founding members of HR, formally incorporating four months after the Haiti earthquake struck [26].

Early activities to support the earthquake response began on January 14 when volunteers created a "Help Haiti Heal" website (helphaitiheal.wordpress.com). Not long after the earthquake struck, the group published a list of "Twitter Commandments," giving other crisis tweeters guidance about sorting accurate from inaccurate rumor, and for "tweeting responsibly" during disasters (Thompson, personal communication).

\section{Twitter Commandments}

1. Do No Harm - It is safer to share no news than to share inaccurate news. Rumors put lives at risk

2. Do Not Panic - You do not need to know it all.

3. Take a Deep Breath - Do not be distracted by noise \& confusion.

4. Verify Source. If you do not know for sure the source is reliable - do not RT the information. Use 2 reliable independent sources for major news.

5. Verify Facts. Get facts, locations, address, specific need, \# of people impacted, population at risk, dig deep into details, the more the better.

6. Listen to the official $\&$ experts. Use caution $\&$ reason $\&$ follow those who appear to have a "handle" on how to respond in these situations.

7. Use Tweak the Tweet - We recommend formatting your tweet using Tweak the Tweet.

8. Not sure where to start? Pick one topic and stick with it. Become an expert on fielding, research facts and providing help on specific topic

9. Repeat the first 3 Twitter Commandments as needed.

Figure 1. Humanity Road's Twitter Commandments

This list represented a formalization of lessons learned from the volunteers' ad hoc but growing experience as crisis tweeters. Thompson claims that the structure of the Commandments offered in complement to the group's online presence helped recruit new members.

\section{Developing Identity as a Virtual Volunteer Organization} Upon incorporation, HR declared their mission:

We are a global citizen's action team of experienced and focused individuals dedicated to educating the public by providing accurate, critical recovery information, before, after and during a catastrophic disaster. We are a nongovernmental not for profit organization aligned with the United Nations global disaster response clusters as well as US state federal and local disaster response groups. We pledge to act responsibly and quickly in identifying, facilitating, collecting and disseminating required information and solutions to the public affected by the event.

This statement strongly echoes the activities they were engaged with at the time: response in an immersive information context of rapid social media posting. The language of "before, after and during" also reflects an underlying awareness of the disaster cycle that includes, along with response and recovery, phases of preparedness and mitigation [6]. Their understanding of the needs of the domain stems from extensive previous volunteer experience by HR leaders Graham and Thompson.

Later, the mission statement was "reduced ... and [made] easier for folks and volunteers to remember" (Graham, personal communication):

Driven by Need, Led By Experience, Powered by Volunteers. Humanity Road's mission is to educate the public before, during and after disasters on how to survive, sustain and reunite with loved ones. Humanity Road volunteers are trained and equipped to use Internet and mobile communications technology to collect, verify and route information online during sudden onset disaster. Using the Internet, they provide public safety information as well as directing the public to governmental and aid agencies that are providing assistance for the disaster.

Though many features from the initial mission statement have been carried over, the new statement more clearly positions HR as a virtual organization that relies on ICT to organize and execute its work. Volunteer activities described here align more closely with earlier efforts by digital volunteers to assist the humanitarian response during the 2010 Haiti earthquake [26] and the 2009 protests in Iran, and are less focused on the concerns of traditional emergency response. Indeed, the organization in its early life is best understood as a sum of the practices of the individuals who identified with the organization. Though they had together forged the new identity and practices of digital volunteerism [26], the distillation of why and what they do together as an organized group emerges through the ongoing work of responding to disaster after disaster around the world. In the data presentation to come, we show this distillation of purpose as it is "discovered" in the conduct of the work, and discuss the effects this has had on making episodic volunteerism viable, on making constant response viable, and on making the event-driven products of work both viable - and, critically, visible.

\section{Membership}

HR relies on a small but steady group of six now-seasoned volunteers who devote considerable time and resources to HR activities both during and between disaster events. ${ }^{1}$ The composition of the team's leadership and core volunteers has shifted since its 2010 incorporation. An aim of the organization is to be " 24 always on, ready to go." In contrast to strategies employed by the non-profits described in Voida et al. [27], HR also regularly leverages a larger temporary workforce of episodic and spontaneous volunteers who activate during disaster events to help the organization meet increased needs during response efforts. Later HR will ask the new volunteers to formally register as members. Of these, some members persist across events

\footnotetext{
1 During 2011, in addition to full-time activity by HR's two leaders, four volunteers responders to more than 30 events each, and three of those reported over 1000 hours of service.
} 
and participate in monthly planning events, and others activate only episodically. The number has gradually risen to about 20 active members. The workforce is global with people reporting in from the U.S. and Canada as well as countries in Africa, Asia, the Caribbean, Europe, the Middle East, and South America - a feature that supports its "24-7" capacity.

\section{Nature of Work}

HR members conduct nearly all their work online: the subject of their work is the online communication that pertains to disaster response and preparation, and the organization works in a virtual, distributed fashion. In this section, we discuss what comprises their work-InBetween Event work and Response-as well as how that work is conducted ("the work to make response work work" to borrow from Bowers [3]).

During a Spring 2012 "All hands conference call"-a monthly meeting that takes place on Skype through a combination of multi-person voice and textual chats-HR members identified their "core business functions" as Disaster Preparedness and Education, Disaster Response, and Process Improvement. This declaration reinforces their mission statement, and then, with the addition of "Process Improvement," makes a move toward overt formalization of their current processes, a topic to which we will return.

\section{In-Between Event Work}

Disaster Preparedness and Education is a long-standing role for the organization that was declared early on in its mission statement. HR devotes considerable resources to preparedness and education, using its website, its @HumanityRoad Twitter account, and the Twitter accounts of several volunteers to distribute "crisis communications" to the public. For example:

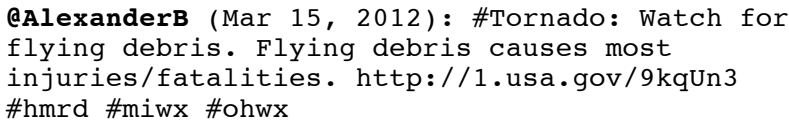

The tweet content aligns to the operational strategy of the group at the time, i.e. whether the group is actively responding to an event or not. Tweets sent during event impact and response periods, called "just in time" messages, are designed for two purposes: to give information about what to do in the moment to those immediately affected and to educate others about how to respond to a certain type of event at a time when HR believes they are most receptive to learning - that is, when an event of a type likely to affect them is happening to someone else.

This next tweet was sent during a time when volunteers were not actively responding to disasters:

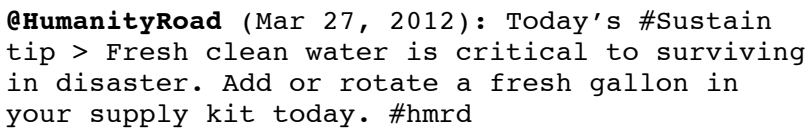

HR conceptualizes this between-disaster period (for them) as a before period for those who are affected by seasonal hazards, which would be some small portion of their global audience. For HR, between periods are times to change focus from the high-action, real-time, information processing activities of event responses, to education messaging concentrating on prevention and preparation advice, an illustration of their structuring of their work visà-vis the external temporalities of disaster events and hazards seasons [18].

Over time, HR has developed a way to standardize preparedness and educational messaging through what they call tweetables, pre-fabricated messages that offer information about how to prepare or respond to specific kinds of disasters. A large percentage of HR's outgoing Twitter communications, including those in the above example, are tweetables. Tweetables serve to structure the social group by constraining, directing and-criticallysustaining, a volunteer's activities with clear things to do during and between events. Inexperienced volunteers can engage in work by retweeting tweetables as they are broadcast by the @HumanityRoad account (an account managed by veteran volunteers), and then moving on to issuing tweetables themselves from the pre-approved list. Issuance of tweetables persistently broadcasts HR's presence and purpose. As tweets are added to the list of tweetables, members continue to define what the group's message is and how it appears to the outside world.

HR's most frequently broadcast tweetable is:

@HumanityRoad: Verify twice. Tweet once. Rumors put lives at risk. \#hmrd

Early crisis tweeters saw verifying as an important aspect of their work [26]. Humanity Road has incorporated these foundational lessons and assumed the role of educator to others about the "right" way to do crisis tweeting.

\section{Response Work}

A central function of HR is Disaster Response. Members process information and collectively create publicly available resources for victims during disaster events. HR's mission statement states that they "collect, verify, and route information," but they also filter, synthesize, and reformat it into standardized data formats.

In the initial period after a disaster event has been identified as a candidate for an $\mathrm{HR}$ response, collection efforts initially focus on improving situational awareness of volunteers so they can make decisions about how they should respond-how much effort should they expend; how much should they shift resources from other HR activities; whether they should activate offline volunteers; how many disaster-based information resources should they create and of what kind; when they should stand down, etc.

As volunteers work to process information for their own situational awareness, and as questions about whether and how to respond are answered through sensemaking 
activities, information-collating efforts simultaneously begin to serve the second goal of creating resources for the affected public and responding agencies. These resources are published and regularly updated on HR's website, linked to in members' outgoing tweets, and routed to other response groups - including those on the ground as well as other remote-response organizations - through tweets, email, conference calls, and in text-based Skype chats.

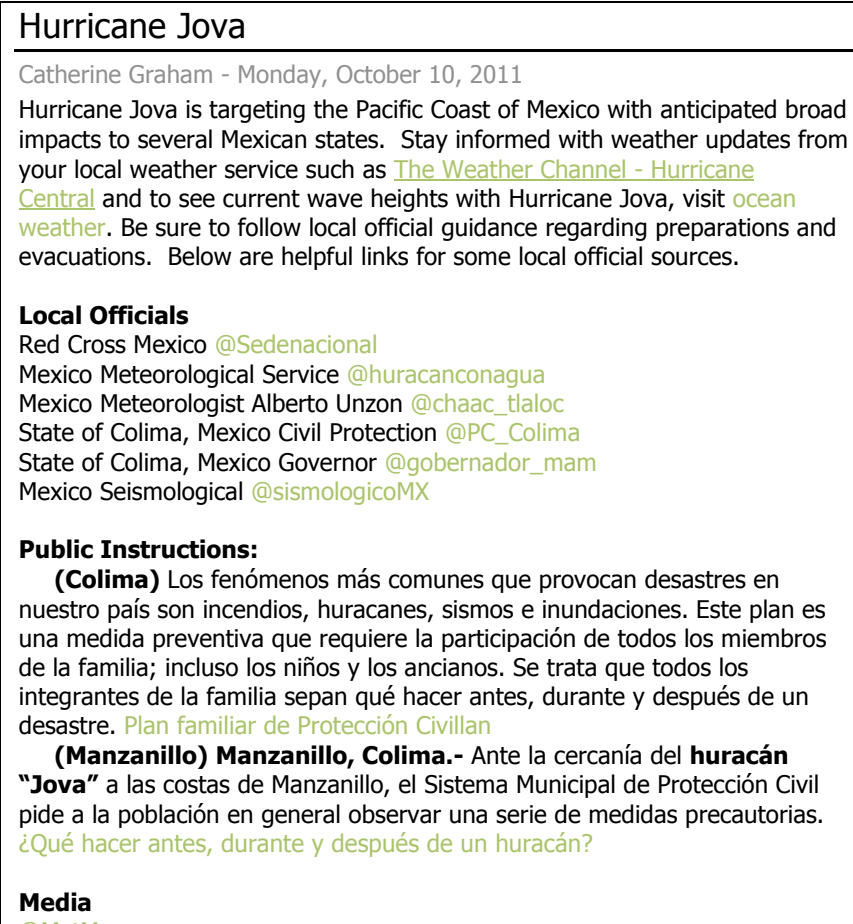

(Colima) Los fenómenos más comunes que provocan desastres en nuestro país son incendios, huracanes, sismos e inundaciones. Este plan es una medida preventiva que requiere la participación de todos los miembros de la familia; incluso los niños y los ancianos. Se trata que todos los integrantes de la familia sepan qué hacer antes, durante y después de un desastre. Plan familiar de Protección Civillan

(Manzanillo) Manzanillo, Colima.- Ante la cercanía del huracán "Jova" a las costas de Manzanillo, el Sistema Municipal de Protección Civil pide a la población en general observar una serie de medidas precautorias. ¿Qué hacer antes, durante y después de un huracán?

Media

Major Hashtags: \#Jova, \#huracn \#hurricane

Micro hashtags: \#Colima \#Vallarta \#Michoacan \#Jalisco \#Nayarit

Figure 2. Event Diary for Hurricane Jova, Original Format

During high-impact events that the group determines to warrant a response effort, an HR member will create an entry within the Event Diary like the one in Figure 2. While many volunteers contribute by reporting information they gather to a shared Skype chat window, a single person, usually one of HR's leaders, creates and edits the Event Diary page. The Event Diaries are by design publicly visible products of the group's efforts to process information during the event, containing a range of information including a high-level account of the event, lists of relevant websites and Twitter accounts, warnings broadcast by official sources, locations and capacities of nearby hospital and shelters, hashtags to follow, etc.

Members turn to Twitter to send information about unfolding events, routing information to both specific people and organizations who are involved in the response as well as broadcasting information to a broad audience.
Widely broadcast information might be intercepted by victims looking for information, or by those trying to help them, or by potential volunteers who might support HR efforts. The outbound tweets closely connect to the information processing activities of the group happening at the time. Selected tweets from HR volunteers during a series of tornados that struck the southeast US in March 2012 illustrate some of this information processing work and resulting Twitter activity:

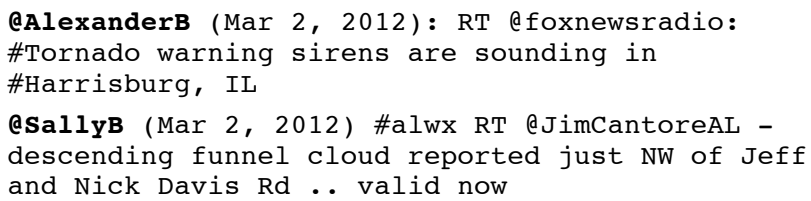

These tweets show HR volunteers retweeting accounts of official sources, amplifying the messages of those accounts. By monitoring their friend/follower networks and executing multiple hashtag searches, volunteers filter the public stream of Twitter messages, identify trusted sources, (including but not only on-the-ground Twitterers), and identify the relevant hashtags to monitor.

Volunteers also respond directly to people in the impact zone of disasters, using @mentions and private direct messages (DMs) to provide preparedness information and relay information about current conditions:

QSallyB (Jan 26, 2011): @madmain You'd best get yourself south of the river--roads are not getting any better!

One of HR's goals is to help people who are "sheltering in place," and they use Twitter to connect and communicate with these "clients" of the organization.

\section{An Extended Examination: Responding to a Large Earthquake, Peru, October 2011}

This section focuses around an extended excerpt of HR activities during a response to a large earthquake in Peru on October 28, 2011. The 6.9 magnitude earthquake struck Peru in the early afternoon, at $1: 56 \mathrm{pm}^{2}$, near the town of Ica. Though later assessment showed the impact of this event to be relatively low, the initial report of earthquake location and magnitude led HR volunteers to activate for the event. The response included eight volunteers, including the first author (hence the reference to "we" in this section), and took place over approximately three hours, beginning informally just minutes after the earthquake, at 2:06 pm, and ending officially when Thompson announced that we were "standing down" at 5:11 pm.

This extended excerpt demonstrates the fluidity of HR's social system-how organizational change, sometimes significant change, occurs while responding to events. In some cases, that change later becomes a fixture around

\footnotetext{
${ }^{2}$ Timestamps for the digital communications presented here are adjusted to be consistent across all volunteer accounts and are normalized around PET, the time zone of the affected area in Peru.
} 
which the group organizes itself, designs its work practice, and even hones parts of its identity.

\section{Using Skype Chats as Virtual Workrooms}

Much of HR's activity occurs on Skype through text-based, synchronous chats. Volunteers participate in several Skype chats at once, with different windows hosting different kinds of conversations: an Urgent Events window hosts real-time response activities; the Useful Links window is a place to post links to websites and tools for use in current or future efforts; volunteers are encouraged to go to the Work Diary window to report their recent activities; and the $H R$ Café is a casual space for off-topic conversation. Occasionally, group leaders or veteran volunteers create a new window for a specific event, or special windows where they invite volunteers from outside HR to collaborate.

Within these virtual workrooms, volunteers come and go throughout the day. Greetings signal to others that a volunteer is available to help if a disaster event occurs. The following excerpt from the HR Café, which occurred in the moments leading up to the October 2011 Peru earthquake, shows volunteers essentially hanging out, mixing disaster talk and availability updates with casual conversation:

Peru Excerpt, Part 1: Skype Chat - HR Café - 10/28/11

HR Sam (1:47:46 pm): Good evening, Hope everyone is well HR Chris (1:48:15 pm): doing well thanks, hope you are too marc123 (1:48:35 pm): evening?! where art thou? HR Sam (1:49:04 pm): Thou art on *** Island, UK

HR Chris (1:49:18 pm): the 5.4 kermadec didnt produce any effects, the Bangkok flooding is still bad - but with language barriers - we have not had much success in that area of the world marc123 (1:49:27 pm): aha. i skipped your kingdom this summer HR Sam (1:50:21 pm): Shame!! My kingdom of ${ }^{\star * *}$ Island is wonderful!

kaitlin_rice (1:52:59 pm): Thanks for the update, Chris! Hi to Sam and Marc!

marc123 (1:53:21 pm): hi!

HR Sam (1:54:31 pm): Hi Kaitlin

kaitlin_rice (1:57:17 pm): Hi Sam. Nice to C U virtually! Sorry I can't chat much now - am working - just made a quick stop at the Cafe - I hope you have a nice weekend!

In addition to coordinating and enacting their response work, HR volunteers also use their virtual chat environment to build community. These backchannel conversations in the HR Café help to strengthen relationships between volunteers, relationships that may be important to sustaining their participation over time.

\section{Activating the "Disaster Desk"}

Just minutes after this casual exchange, HRSally shares two posts in the HR Urgent Events window:

Peru Excerpt Part 2: Skype Chat - HR Urgent Events 10/28/11 ${ }^{3}$

1 HR Sally (2:06:30 pm): http://earthquake.usgs.gov/ earthquakes/recenteqsww/Quakes/ at00ltshuy.html HR Sally (2:06:51 pm):

${ }^{3}$ This is the beginning of a long excerpt revealed in sections throughout this paper. Line numbers indicate progression of this conversation within the HR Urgent Events window.

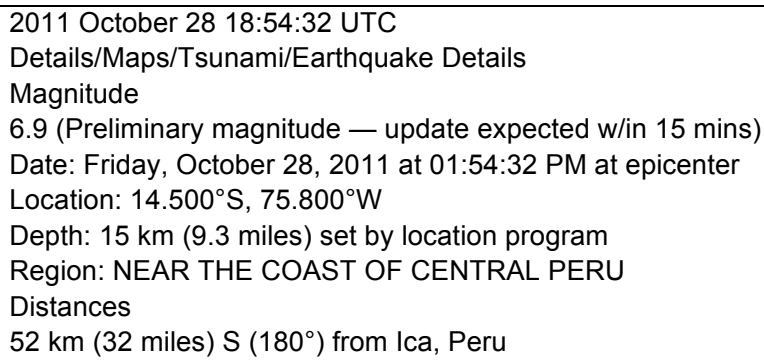

Sally had been online, tweeting, when she reported about the earthquake. Her first post in the Urgent Events window (line 1), about 12 minutes after the earthquake, was a link to the United States Geological Survey (USGS) website page generated for this event, and the second post (lines 2-13) was an earthquake report copied and pasted from it. This post became the starting point for HR's work around the quake. The conversation continued:

Peru Excerpt Part 3: Skype Chat - HR Urgent Events - 10/28/11

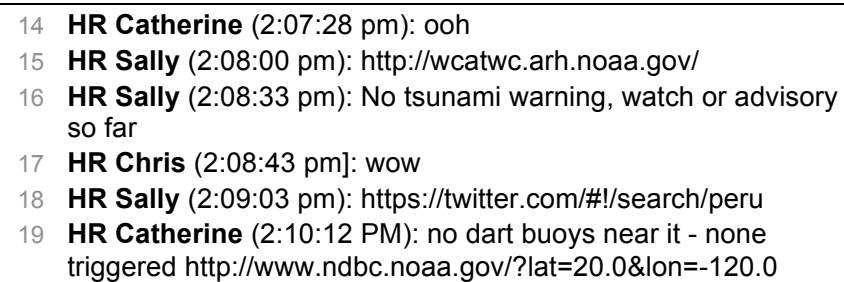

HRCatherine, one of the two HR leaders, was the first to respond to HRSally's post. Her short comment (line 14), "ooh," signaled that she had seen HRSally's post, and that perhaps this could be a significant event requiring humanitarian response. HRChris's "wow" remark (line 17) imparted the same effect. These are often the conditions for activation of HR's Disaster Desk.

The Disaster Desk, operated from HR's Skype chatrooms by one or multiple members, is the active state of the volunteers during disaster response efforts, but has also come to imply the monitoring of possible events as well. At a minimum, its most commonly understood description is a set of pre-articulated tasks that volunteers complete during events, such as monitoring social media for information, verifying and analyzing information, and communicating situational awareness and response information.

The four other posts in Part 3, which all occurred soon after HRSally's first post, show the activation of HR's Disaster Desk. HRSally and HRCatherine moved quickly to selfselected tasks, executing Twitter searches (line 18) and checking for tsunami reports (lines 15-16; 19).

\section{Division of Labor and ICT Tool Use}

In the next section of the excerpt, volunteers began to coordinate their activity, explicitly articulating their intentions to take on specific tasks using specific tools.

Peru Excerpt Part 4: Skype Chat - HR Urgent Events - 10/28/11

20 HR Catherine (2:10:28 PM): I'm in Tweet tracker so i'll take a look there 
1 HR Chris (2:10:41 PM): I am @HR and will begin tweeting kaitlin_rice (2:13:38 PM): I can RT from kaitstweets for a few

In this excerpt, three experienced HR members explicitly announced their intentions for what they planned to work on next. These declarations are important for creating a shared awareness of distributed coordination.

Part 4 also indicates a relationship between ICT and the division of labor. HR volunteers use several applications during their response efforts. Here we see volunteers turning to Twitter in different ways to gather and disseminate information. For the former task, different tools allow different forms of mining-e.g. the TweetTracker tool [16] referenced here is a tweet analysis tool for disaster relief that collects and maps tweets with geolocation metadata. There is no single tool that HR uses to do all of their Twitter monitoring - no tool that allows them to filter by multiple terms and hashtags, filter by geographic range, translate, and geolocate tweets all in the same place. For this reason, volunteers select different third party Twitter applications, often ones with which they are uniquely proficient. The division of labor is therefore shaped by tool as well as by task.

Through the selection of these tools and tasks, human capacity, tool capacity, and the functions of the organization become mutually structuring. The affordances of available tools enable the organization to take on certain types of tasks. Over time, by selecting or being assigned to certain types of tasks that require certain tools, members develop expertise in different areas, and this collective expertise comes to shape the overall work practices and work products of the organization.

\section{Identifying On-the-Ground and Official Sources}

Some of the first tasks that volunteers take on during disasters are identifying on-the-ground and official sources. Gathering information from these sources fits the larger goal of increasing situational awareness-for themselves, victims, and responders - and will later become the raw material for the resources that members generate. The following passage from the excerpt shows members moving to identify these sources, verify them, and pull information from them into their shared workspace.

Peru Excerpt Part 5: Skype Chat - HR Urgent Events - 10/28/11

\begin{tabular}{|l}
23 HR Catherine (2:14:19 pm): This Author appears to be in the \\
area of the quake \\
24 Author: dsanchez \\
25 Location:Lima \\
26 Date-Time:2011-10-28 12:04:35 \\
27 Tweet:Joder, magnitud 7 en Ica \#Terremoto \#Temblor \\
28 Latitude:-12.0459739, Longitude:-77.0306154 \\
29 \\
30 \\
HR Sally (2:16:13 pm): Ica (32 mi), Chincha Alta (76 mi), \\
Puquio (114 mi) and Lima *186 mi) are nearest towns/cities-- \\
seeing tweets that buildings in Lima shook. \\
31 HR Catherine (2:17:42 pm): Sorry dsanchez is in LIma - the \\
tweet was located in Peru my mistake \\
32 HR Chris (2:17:45 pm): anybody got an official source? \\
33 HR Chris (2:17:59 pm): s'ok - I am seeing reports that the \\
\hline
\end{tabular}

quake was felt in Lima

HRCatherine's first post (lines 23-29) in this section contained information she found using TweetTracker in her quest to locate on-the-ground sources. On line 30, HRSally was also searching for information from the ground, using an Advanced Twitter Search that lets her set geographical boundaries for the search and therefore pick up tweets likely to have originated in the affected area. Both Tweet Tracker and the Advanced Twitter search, because they rely on tweet metadata and user-reported information to determine location, provide incomplete and sometimes inaccurate results. However, volunteers work to verify sources both individually and collectively (e.g. lines 30-33).

The "Checklist": Dynamic Inscription of Process

At this stage of the event response, about 30 minutes after the earthquake, there were three volunteers working the Disaster Desk, collecting information and sharing it with each other in the Urgent Events window.

At 2:30pm HRChris suggested to HRCatherine, her coleader, that they initiate an Event Diary (see Figure 2). At about this time, several people checked in to offer help:

Peru Excerpt Part 7: Skype Chat - HR Urgent Events- 10/28
HR Chris (2:30:27 pm): Cat - event diary page?
35 HR Catherine (2:32:45 pm): Yes Chris, I think this should be an Event Diary
HR Sam (2:35:04 pm): what would u like me to do?
HR Sam (2:35:21 pm): monitor?
Deepak (2:36:22 pm): Can I help in any way?
40 Kate Starbird - student/researcher (2:36:56 pm): Let me know if I can help as well.

$36 \quad \ldots$

In the initial part of the response (Excerpts Parts 1-6), the effort was largely decentralized with volunteers following established patterns. However, as more people, some of them inexperienced, joined the chat and offered to help, a need arose for a more explicit and directed division of labor. HRChris began proposing tasks to the group at large to populate the Event Diary (lines 41-46), but then moved on to assigning them to specific volunteers (lines 48-51):

Peru Excerpt Part 8: Skype Chat - HR Urgent Events- 10/28/11

41 HR Chris (2:37:30 pm): we need the official weblinks for national and regional - the FEMA like links for Peru

42 HR Chris (2:38:13 pm): we are creating an event page

43 HR Chris (2:39:17 pm): Use this page as a template of the types of links to collect http://www.humanityroad.org/EarthquakeTurkey

44 HR Chris (2:39:37 pm): Also the useful links window contains our official checklist of what we do on an emerging event

45 HR Chris (2:40:31 pm): We also need someone to monitor for urgent needs

46 HR Chris (2:40:40 pm): so just tell us which piece you are working on

$47 \quad \ldots$

48 HR Chris (2:42:43 pm): Deepak - can you monitor Tweet tracker for urgent needs? Kate - can you Google search for information on impacted hospitals, buildings, people

$49 \quad$..

50 kaitlin_rice (2:43:21 pm): Please repeat nearest cities to epicenter 
51 HR Chris (2:43:21 pm): Sam - can you collect the best twitter ids to monitor - some are already in this window

This represented a significant shift in activity coordination. In the early stages of the response, a few experienced volunteers appeared to be self-organizing by self-selecting tasks, differentiating them from others, and then articulating these to the group. That small group's efforts were largely guided by pre-established routines that these experienced volunteers intersubjectively shared. Some of the volunteers joining the efforts later did not share this knowledge, which required a shift from a mostly leaderless, self-organizing style to a more hierarchical, centralized one.

Attempting to both direct and educate, HRChris then pointed to two digital documents that contain information about how the organization "works" during disasters: the Event Diary page (like the one in Figure 2) that had been created for a previous event, and the official Checklist which she posted in the HR Useful Links window:

Peru Excerpt - Checklist - HR Useful Links- 10/28/11

\section{HR Chris (2:16:40 pm): Checklist}

HR Chris (2:16:48 pm): What happened, did it really happen, where, when, details

If yes - share information on texting

If no - share information on verifying before tweeting

Who is the Event Official Source

Examples: Hurricane, Tornado, Flood, Earthquake, Wildfire, Health

What is the potential impact to the population

Examples: collapsed buildings, approaching fire, tornado, storm

The routine prescribed in the Checklist encapsulates a cluster of organizational know-how, including pre-existing domain knowledge and lessons learned from experience by HR's members. The Checklist is a dynamic document, built through members' media monitoring experiences as digital volunteers, and continuously evolving as members incorporate lessons learned and leaders seek to clarify and streamline the inscribed work process. Existing as a digital document that can be copied and pasted into current activity windows or electronically distributed as a PDF file, the Checklist is a resource that leaders and experienced volunteers use referentially in their own work practice and prescriptively when training others. In both capacities, the Checklist, as well as the Event Diary from an earlier event, are elements that structure the organization and its work. Digital documentation of action facilitates the structuration: that is, what we just did becomes what we do. Action and routine have a recursive, co-adaptive relationship [10].

An Innovative Return to the "Self-Directed Team Approach" At this point in the excerpt, a problem with the current work practice became clear to several volunteers: the multiple, simultaneous use of the HR Urgent Events window as a place for activity coordination, information sharing and resource building, as well as the staggered arrival of new volunteers onto the virtual scene of the response efforts, resulted in a confusing work environment. While some tasks were being repeated, others were forgotten, and even though volunteers made an effort to articulate their intentions and their actions, it was hard for members to keep track of what was being done. Addressing this problem, one of HR's leaders introduced a new tool, which readily changed not only the activity in the moment, but also how the organization would respond to subsequent disasters when multiple volunteers are active.

Following a request by kaitlin_rice for information about nearest cities (Part 8, line 50), Sally dropped her current task and went to retrieve that information. As she was posting the distances to the window for the second time (lines 53 \& 55), another episodic volunteer, Jiro, joined the conversation:

Peru Excerpt Part 9: Skype Chat - HR Urgent Events- 10/28/11

\section{Jiro (2:43:34 pm): whats up guys!}

53 HR Sally (1:43:54 pm): [3:16:09 PM] HR Sally: Ica (32 mi), Chincha Alta (76 mi), Puquio (114 mi) and Lima *186 mi) are nearest towns/cities--seeing tweets that buildings in Lima shook.

kaitlin_rice $(2: 44: 02 \mathrm{pm}):$ TY

HR Sally (2:44:30 pm): [3:06:42 PM] HR Sally: Distances

$52 \mathrm{~km}$ (32 miles) $\mathrm{S}\left(180^{\circ}\right)$ from Ica, Peru

$122 \mathrm{~km}$ (76 miles) SSE $\left(163^{\circ}\right)$ from Chincha Alta, Peru

HR Chris (2:44:38 pm): hello Jiro

Kate Starbird - student/researcher (2:45:07 pm): no damage immediately reported ... http://www.bloomberg.com/news/201110-28/peru-hit-by-magnitude-7-quake-tsunami-center.html

61 Jiro (2:45:13 pm): hello Chris, i have been offline for a while because of low current here in my area

HR Chris (2:46:10 pm): (thumbs up)

The interaction grew confusing. Coordination and communication problems began to take a toll on efficiency. Work became redundant, and responses began to arrive out of order. Though these activity coordination efforts already reflect some adaptation to the affordances of Skype-for example, how volunteers explicitly articulate availability and current tasks - this response effort brought to light some of its constraints. A few minutes later, HRChris acknowledged the issue, exclaiming:

\section{HR Chris Thompson (2:51:13 pm): < insert process} improvement on data collection here $>$

Under the stress of the situation, with too many people doing too many things at once, the socio-technical infrastructure that underlies their work practice was breaking down. Star and Ruhleder [25] explain that infrastructure becomes visible only at these points of breakdown. Volunteers directed their attention to their social configuration as the critical infrastructure here (the technical infrastructure remains taken-for-granted). At 2:57pm, not quite an hour after HR began its response to the Peru earthquake and about six minutes after HRChris's remark about the need for "process improvement," HRCatherine posted a link in the HR Urgent Events window introducing a Google Docs spreadsheet to help coordinate their information collation activities.

4 HR Catherine Graham (2:57:56 pm)

https://docs.google.com/document/d/5555555 
65 HR Catherine Graham (2:58:54 pm): I have created a document to collect the items we need for publishing i.e. put hospitals links in the links column. I'll start collecting whats already here in the urgent window for it

To create the Event Monitoring Google Doc (Figure 3), HRCatherine pulled the categories in the left column directly from an Event Diary entry created for a previous event (Figure 2).

Humanity Road Event Monitoring

6.9 Peru Earthquake

Volunteers reporting in: Alexander, Kate, Sally, Chris, Cat, Kaitlin, Sam

\begin{tabular}{|c|c|}
\hline National and Regional Links & $\begin{array}{l}\text { @.AlertaNews } 24 \\
\text { @info_emergencia } \\
\text { http://www.peru.gob.pe/ }\end{array}$ \\
\hline Emergency Numbers & $\begin{array}{l}\text { Ambulance: } 131 \text { Fire: } 132 \text { Police: } \\
\text { 133. } 137 \text { maritime emergencies, } \\
\text { Conaf } 130 \text {, PDI } 134 .\end{array}$ \\
\hline $\begin{array}{l}\text { Nearest Airports } \\
\text { (Kate looking) }\end{array}$ & $\begin{array}{l}\text { Pisco Airport (PIO) GPS: } 13^{\circ} 44^{\prime} \\
41^{\prime \prime} \mathrm{S}, 76^{\circ} 13^{\prime} 13^{\prime \prime} \mathrm{W}\end{array}$ \\
\hline $\begin{array}{l}\text { News and Social Media links } \\
\text { (Sam Getting) }\end{array}$ & $\begin{array}{l}\text { @Info_emergencia } \\
\text { @SubTVChile@terratvperu } \\
\text { @news_in_peru } \\
\text { @AlertaNews24@@perutweet }\end{array}$ \\
\hline $\begin{array}{l}\text { Hashtags } \\
\text { (Sam Getting) }\end{array}$ & $\begin{array}{l}\text { \#pisco \#peru \#sismo } \\
\text { \#Earthquake \#Temblor \#Lima }\end{array}$ \\
\hline$\ldots$ & $\ldots$ \\
\hline
\end{tabular}

Figure 3. Replica of Google Doc for Event Monitoring.

The black text represents the original state of the document. Black

plus blue (or gray) text is an intermediate state at 3:08am PET

The Event Monitoring Google Doc is a manifestation of existing HR work practices; however, the shift from single editor control to all-member control that the Google Doc afforded had radical consequences on the way the group conducted its work. Within ten minutes, seven volunteers were working there, and the chat rooms suddenly quieted. Both long-term and episodic volunteers used the format to guide collection efforts. Working together, they quickly moved the previously collected information to this document, and continued to fill in other areas.

Further adaption of this document occurred to support coordination when we realized we needed to know who was working on what parts. We soon developed a technique of writing our names in the left column of the row we were working on. Newly arrived volunteers no longer needed to be told what to do, and people did not have to additionally monitor the work of others through the chat windows. Instead, members looked for holes in the document and began working to fill them. Speech acts in the chat window were no longer as frequently required because the work activity itself was now visible and members were mutually aware [5]. In other words, the articulation work [24], which had to be made explicit previously, became in part implicit by being embedded in the document and in the actions taken upon the document.

Not long after this socio-technical reorganization, the group completed the document, and HRCatherine copied the Google Document directly into the Event Diary blog entry on the HR website (Figure 4).
The Google Doc approach for organizing and generating the Event Diary thereafter became standard for organizing response efforts when multiple volunteers were reporting. It also replaced the overt, verbal top-down organizing that had become necessary by the linear nature of the Skype chat environment, shifting back to a "self-directed work team approach," the intended operational strategy of the organization (Graham, personal communication).

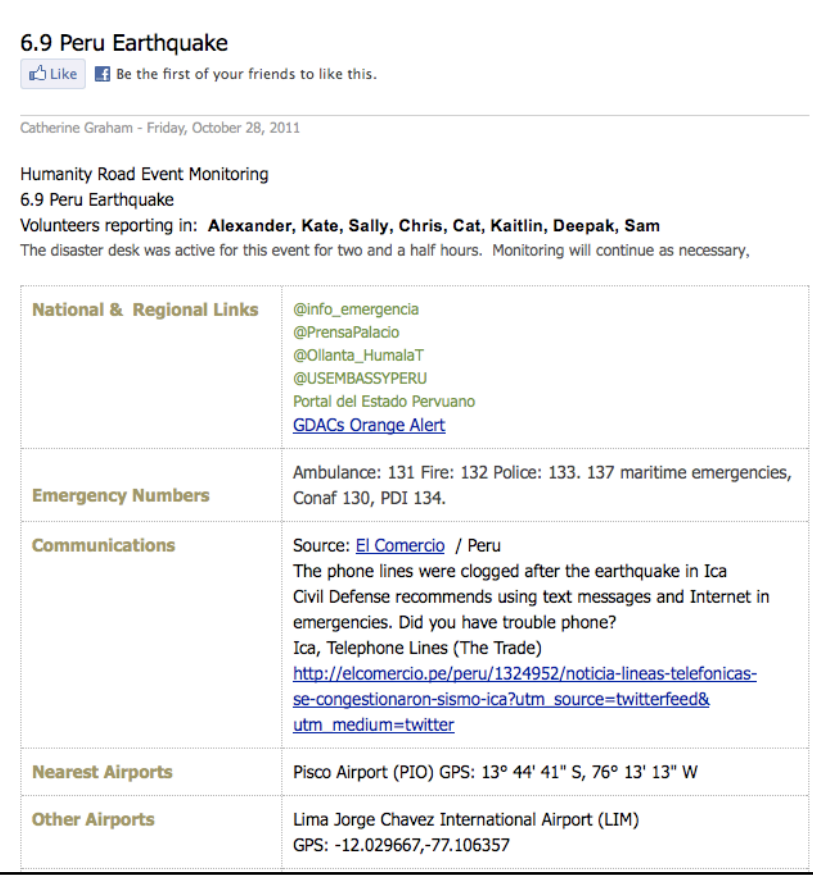

Figure 4. Event Diary Reflecting Google Document Structure

With this adaptation, the overall direction of the work had become more teleological than before-that is, more designed toward a clear, shared end goal-eliminating the tax of overt verbal orchestration, which re-enabled independent work. The Google document, then, became a replacement form of top-down organization, but also created new degrees of freedom for the organization and its individual members.

As the group moves forward to subsequent events, we discover that this innovation enables episodic volunteers to more freely enter and exit. This allows the organization to take advantage of the around-the-clock, around-the-world coverage that the inclusion of episodic volunteers makes possible. In turn, the reduction in moment-by-moment oversight allows long-term volunteers to diversify their attention to other organizational goals.

\section{DISCUSSION}

We now expand the discussion to consider the larger environmental and institutional context in which this organization exists. Externalities structure internal operations, and shape decisions about who the personnel are and what they do. The desire to be a legitimate change agent within the larger ecosystem of emergency response refines how they express and organize around what we 
believe to be their ultimate objective - to be stewards of the virtual "knowledge commons" [11].

\section{Positioning vis-à-vis External Temporalities}

A dominant feature of disaster events is their temporal ordering, or perhaps their temporal disordering. Human life in part organizes around the temporality of the world around it: biological temporality, environmental temporality, and - to a degree that often overrides these seemingly incontrovertible natural temporal orders-the socio-temporality of social institutions like the schedule, the week and the work shift $[28,29]$. Disasters might be one of the few natural events that override the socio-temporal order; indeed, damage to the routines of social life is a defining characteristic that separates disasters from local emergencies and other disruptions.

What, then, of organizations that exist to respond to such unexpected calamities? Older, physical-space emergency response organizations have established what it means to continue to work even between disaster events. The American Red Cross, which is federally mandated to respond to domestic disasters, maintains a relatively small group of employees at the national level. They respond by expanding [7] with certified volunteers who activate to support the site-based headquarters and shelters.

The ambitions of HR to respond to events globally puts demands on the pace of work. Their early mission therefore places them in a struggle between the external temporalities [18] of the subject of their work and the limits of their internal resources to do that work. Over time, these conflicts give rise to questions about how to temper the relentless surprise of world-wide disasters, and the answers come in part through its workforce composition.

\section{Sustaining through Episodic Volunteerism}

Humanity Road emerged from on-line spontaneous volunteerism [12]. Unlike other non-profits in the disaster domain as well as elsewhere who understandably see this workforce as too taxing to the organization [27], HR continues to accept spontaneous volunteers into its activities. As they have implicitly conceptualized it, episodic volunteerism supports the basic requirements of a disaster organization: to be alerted as fast as possible from any reliable source and to respond around-the-clock until the effects of a disaster reaches some stable point.

However, as we have seen in the excerpt presented in this paper, incorporating episodic volunteers takes work by the organization; HR is essentially "baking in" mechanisms into their work that make this operational strategy possible. They are even defining their work around the capacities and limitations of this workforce, co-adapting their membership and work practices with what their particular brand of worker can do. They rely on experienced volunteers to quickly train new recruits, who give them well-scoped tasks initially. Later, when response efforts stabilize, HR attempts to recruit them into official membership, asking them to register on HR's website and to participate in volunteer training. The organization has formalized several simple tasks to assign to inexperienced volunteers, including media monitoring of specific feeds looking for specific kinds of information (e.g. Part 8) and outgoing messaging using precrafted tweetables. As time goes on, volunteers are given increased amounts of responsibility, an indication of their centrality to the organization [17].

However, organizational social "processes" were not enough, as demonstrated earlier, to sustain HR's work from event to unexpected event. The composition of HR's members created the conditions for an innovation that only slightly adapted an existing work practice, but significantly transformed the coordination abilities of the organization.

\section{Negotiating a Place in the Ecosystem of Disaster Response}

In the two years since incorporation, HR's rapid evolution has brought it to the point of wrestling anew with the limits of its responsibilities in a new craft that it is in large part responsible for creating.

\section{A Matter of Ethics}

How do they decide to whom they respond? What resources limit them? What happens when little information is coming from a disaster site, and they have no local volunteers? During fatal flooding and mudslides near Rio de Janeiro in Brazil in January 2011, HR recruited three Brazilian volunteers who helped the group understand the geographical and cultural aspects of the disaster and translated incoming and outgoing communications. HR was then able to support the event for several weeks. A comment indicates that HR had less success supporting similar flooding events in other parts of the world:

HR Chris: ... the Bangkok flooding is still bad - but with language barriers - we have not had much success in that area of the world

Recently, in late summer of 2012, an HR principal wrote to her cadre of volunteers responding to multiple simultaneous events around the world:

Thought for the day: with 195 countries (one can debate that number) in the world - it is ok to focus on those we can truly help and explain why we are not as effective in or on behalf of those we can not provide as much help.

This ongoing process of reflection indicates that the organization is working toward a degree of sustainability where choices regarding limits especially as they relate to the ethics of disaster response must be explicitly made.

\section{A Matter of Relevance}

What are the ways in which a virtual volunteer organization can leave its mark on the field of practice they are trying to create? Asking this question indicates another longer-term view toward sustainability. Above, we note how HR uses outgoing tweets to instruct members of the public on how to best use social media during disaster. HR has also developed formal relationships with emergency managers to educate them on how to leverage social media as well as digital volunteers during emergency response. 
As another clear indication of their desire to align with the institution of emergency response, on July 27, 2012, the HR principals renamed Event Diaries to Situation Reports, or "sitreps" as they are colloquially referenced in the emergency management world. When queried about this shift, they say:

[We] made the change...to more closely align with common verbiage used by emergency response organizations and improve search engine results for finding information about recent events supported by Humanity Road. "Event Diary" is somewhat casual and seems to portray past tense but "Situation Report" provides a more current description of information contained within the site....this more accurately reflect(s) the information we are providing to the public and to aid agencies...

Working toward Inclusion in the Ecosystem of Emergency Response as a Change-Agent

This research highlights an ultimate challenge for the organization and for other groups of digital volunteers: How might they have influence? And in this particular case, how might they connect their efforts with the processes of formal emergency and humanitarian responders?

For HR, their consistent production of Event Diaries (now Situation Reports) is one way they attempt to address this challenge. By continually working to collect and synthesize information during events, and by making this work visible, HR is demonstrating some of the new capacities of digital volunteerism. They are not alone in these efforts; Standby Task Force has similar aims to establish a similar role for themselves in the ecosystem of emergency response.

In the context of disaster, social media and other ICT are enabling the manifestation of a "knowledge commons" [11], a shared information space for victims, onlookers, and the convergent digital volunteers. We interpret HR to be acting as a "steward of the commons" [11] through its consistent activity to organize the data there into visible, consumable information. In doing so, its members simultaneously model this behavior for others who might want to constructively participate online, an activity that complements its explicit work to educate others. Ostrom claims that "governing the commons" is best done by community members and not external authorities [21], and we see this happening naturally here early in the life of such a burgeoning commons. However, since HR members (alongside other digital volunteers) are helping to create the commons by making it more visible and navigable for the purpose of broader participation, we see HR's objective as striving towards a future where emergency managers not only recognize the existence of the commons, but then also move into the role of participants of the commons.

To meet the dual objectives of maintaining a usable knowledge commons and connecting those efforts to formal response, HR believes that it must educate the emergency response community through persistent demonstration of rigorous practice and production. In effect, the work of collectively organized digital volunteers is out ahead of the institution of emergency response. Volunteers organize virtually to process information, but many affected people and responders do not yet know to tap these new collated information resources and the workforce behind them. In probably most cases, formal responders and victims do not even know that such trustworthy efforts exist.

What we are seeing is that $\mathrm{HR}$ - as part of a growing movement of responsible advocators of social media in emergency response-is trying to show not that social media alone is the answer to disaster's problems, but rather that the collective system of people and data that underlie it can be shaped into new forms of rapid, highly localized assistance. Through persistent work in disaster after disaster, HR has steadily uncovered and crystallized their organizational mission and the practices that make episodic voluntary participation viable. In its display of the work, $\mathrm{HR}$ is trying to demonstrate worth, be visible, and ultimately be a change agent to the very traditional system of emergency management.

\section{Conclusion}

We examine a case of a purely virtual organization based on volunteerism in disaster response-Humanity Road. Its origins arose largely from the spontaneous convergence of people who reacted to news of disaster events by coming into the social media space, listening and looking for information. Those who persisted saw an opportunity to create an organization that could formalize a set of information processing activities, including collating and verifying the stream of information produced in disaster situations. The group negotiates tasks, division of labor, membership and objectives with respect to its internal resources and its ambitious aims of serving an external purpose that places high demands on the temporal ordering of work - that of helping others by changing and finding a new place in the ecosystem of emergency response.

The challenges of sustaining a public service group based entirely on volunteerism are in part mitigated by designing the very heart of the work to leverage such a workforce. In addition, with a commitment to global response, and sensitivity to limitations of their cultural knowledge, HR essentially makes it a self-requirement to access episodic volunteers from the locality they want to support. Humanity Road's inclusion of episodic volunteers also goes to an ideology of "the commons," which we propose shapes their ultimate objective: to participate in emergency management as a change agent by introducing new forms of work and work production to benefit the institution.

\section{ACKNOWLEDGMENTS}

We thank Humanity Road for granting us access to the inner workings of their organization and for being so generous with their time-helping us to understand their history, mission, and day-to-day organizing. We thank both the anonymous reviewers for their insightful critique, and Edwin Hutchins for comments on early work. We are also grateful to the US National Science Foundation, which funded this research through a Graduate Research Fellowship and grant IIS-0910586. 


\section{REFERENCES}

1. Ahuju, M.K., \& Carley, K. Network structure in virtual organizations, Journal of Computer-Mediated Communication, 3, 4 (1998).

2. Anderson, K. \& Schram, A. Design and Implementation of a Data Analytics Infrastructure In Support of Crisis Informatics Research. In the 33rd Intl Conference on Software Engineering, (2011) 21-28.

3. Bowers, J. The Work to Make the Network Work: Studying CSCW in Action. Proc. CSCW 1994, ACM, (1994) 287-298.

4. DeSanctis, G., P. Monge. Communication processes for virtual organizations. Organization Science, 10, 6 (1999), 693-703.

5. Dourish, P. \& Bellotti, V. Awareness and Coordination in Shared Workplaces. Proc. CSCW 1992, ACM (1992) 107-114.

6. Drabek, T. E. Human Responses to Disaster: An Inventory of Sociological Findings. New York: Springer-Verlag, 1986.

7. Dynes, RR. Organized Behavior in Disaster. Heath, 1970.

8. Finholt, T., Sproull, L., \& Kiesler, S. Communication and performance in ad hoc groups. In J.Galegher, R.Kraut and C.Egido, (Eds.), Intellectual teamwork (pp. 291-325). NJ: Lawrence Erlbaum Associates, 1990.

9. Fritz, C. E. \& Mathewson, J. H. Convergence Behavior in Disasters: A Problem in Social Control, Committee on Disaster Studies, National Academy of Sciences, National Research Council, Washington DC, 1957.

10. Giddens, A. The Constitution of Society: Outline of the Theory of Structuration. University of California Press, 1986.

11. Hess, C. and Ostrom, E. (Eds) Understanding Knowledge as a Commons: From Theory to Practice. Cambridge, MA: MIT Press, 2006.

12. Hughes, A., L. Palen, J. Sutton, S. Liu, \& S. Vieweg. "Site-Seeing" in Disaster: An Examination of On-Line Social Convergence. Proc. of Information Systems for Crisis Response and Management Conference (ISCRAM) 2008.

13. Humanity Road. 2010 Annual Report. Humanity Road, Inc. (2011) Boydton, VA. Available at:

www.humanityroad.org

14. Kendra, J.M. \& Wachtendorf, T. Reconsidering Convergence and Converger: Legitimacy in Response to the World Trade Center Disaster. Terrorism and Disaster: New Threats, New Ideas: Research in Social Problems and Public Policy 11, (2003), 97-122.

15. Kreps, G. A. \& Bosworth, S.L. Organizing, Role Enactment, and Disaster: A Structural Theory. Cranbury, NJ: Associated University Presses, 1994.
16. Kumar, S., Barbier, G., Abbasi, M.A., \& Liu, H. TweetTracker: An Analysis Tool for Humanitarian and Disaster Relief. In Proc. of ICWSM (2011), 661-662.

17. Lave, J., \& Wenger, E. Situated learning: Legitimate peripheral participation. Cambridge University Press, Cambridge, UK, 1991.

18. Lervik, J.E., Fahy, K.M., \& Easterby-Smith, M. Temporal dynamics of situated learning in organizations, Management Learning, 41, (July 2010), 285-301.

19. Malone, T. W., Laubacher, R. \& Dellarocas, C. N., Harnessing Crowds: Mapping the Genome of Collective Intelligence (February 3, 2009). MIT Sloan Research Paper No. 4732-09.

20. Orlikowoski, W. J. The duality of technology: rethinking the concept of technology in organizations. Organization Science, 3, 3 (1992), 398-472.

21. Ostrom, E. Governing the Commons: The Evolution of Institutions for Collective Action. Cambridge, UK: Cambridge University Press, 1990.

22. Preece, J., \& Shneiderman, B. The Reader-to-Leader Framework: Motivating Technology-Mediated Social Participation, AIS Transactions on Human-Computer Interaction, 1(1) (2009), 13-32.

23. Putnam, L.L., Nicotera, A.M., \& McPhee, R.D. Introduction: Communication Constitutes Organization. In Building Theories of Organization: The Constitutive Role of Communication, Putnam, L.L. \& Nicotera, A.M. eds., Routledge, New York, 2009.

24. Schmidt, K. \& L. Bannon. Taking CSCW Seriously: Supporting articulation work. Computer Supported Cooperative Work Journal, 1, 1 (1992) 7-40.

25. Star, S.L. \& Ruhleder. K. Steps towards an ecology of infrastructure: complex problems in design and access for large-scale collaborative systems. Proc. of CSCW 1994, ACM, (1994) 253-264.

26. Starbird, K. \& Palen, L. "Voluntweeters:" SelfOrganizing by Digital Volunteers in Times of Crisis. Proc. of CHI 2011, ACM, (2011) 1071-1080.

27. Voida, A. Harmon, E. \& Al-Ani, B. Bridging between organizations and the public: volunteer coordinators' uneasy relationship with social computing. In Proc. of CHI 2012. ACM, (2012) 1967-1976.

28.Zerubavel, E. Patterns of Time in Hospital Life: A Sociological Perspective, University of Chicago Press, 1979.

29. Zerubavel, E. The Seven-Day Circle: The History and Meaning of the Week, Free Press, 1985. 